\title{
Diamonds of Arkhangelsk kimberlite province (review)
}

\author{
Garanin, V.K. ,Kudriavtseva, G.P. , and Possukhova, T.V. \\ Geological Faculty, Moscow State University, Vorobiovy Gory, 119899, Moscow, Russia
}

Arkhangelsk kimberlite province (AKP) is the largest diamondiferous province in Europe. It was discovered in the end of $70 \mathrm{th}$. Nowdays there are enormous data on geology, petrology and mineralogy of diamond, its minerals-satellites and kimberlite rocks for kimberlite pipes of this region. All these data are shown on specific (typomorphic) features of diamonds from rocks of this important kimberlite province of the world.

\section{Morphology}

The main specific (typomorphic) feature of diamonds of Arkhangelsk province is a predominant distribution of round rombododecahedra (about 60-80\%) among diamonds in kimberlite pipes of the Lomonosov deposit (Zolotitskoye field). The following on distribution are rounded tetrahexahedra (5-20\%). Quantity of octahedral crystals is sharply increased (up to 80\%) only in a small-sized classes $(-1+0.5 \mathrm{~mm})$. It is established that the diamonds in each pipe of deposit are characterized by individual morphological features. For example, the quantity of rounded diamonds varies from pipe to pipe (from $45 \%$ in the Lomonosov pipe up to $71 \%$ in the Pomorskaya and the Karpinskaya-1 pipes). Characteristic feature of diamonds from this deposit is presence of curve surfaces with corrosion sculptures and channels. At transition from large classes to the small-sized ones the content of the safe stones sharply reduces (almost in a half). The contents of diamonds with corrosion sculptures and channels for the Lomonosov deposit as a whole makes up about 40 weight \%. Among octahedral crystals more than half have isometric forms with a high degree of safety, and among dodecahedron crystals less than $20 \%$ have isometric forms, and other diamonds bear traces of plastic deformation. There are sharp distinctions in process of crystallization of these two main groups of crystals. Thus the crystallization of octahedral crystals occured in more stable conditions. Dodecahedral crystals were subjected to oxidizing solution. At transition from diamondiferous Zolotitskoye field to low-diamond-bearing Verkhotinskoye one and further to nondiamond-bearing Kepinskoye and Soinskoye fields the diamond potential sharply decreased with presence in the pipes the fragments of heavy frosted polycrystalline aggregates of small-sized diamonds with an intensively dissolved surface down to formation on the deep horizons of some pipes the skeletal boxed crystals (Garanin et al., 1991; Makhin, 1991; Zakharchenko, 1994).

\section{Internal structure}

Most of diamond crystals have nucleas (core) of earlier diamond. Growth of crystals took a place on unstabil conditions. Most of crystals have zoning, zoning-sectorial and fibrous structures or their combinations. Such structure are indicated on diamond crystallization in enviroment with various phisical-chemical conditions, with interupts of crystallization process, with periods of solution, mechanical crushing etc. (Garanin et al., 1997).

\section{Physical properties}

One group of kimberlite pipes from the M.L. Lomonosov deposit (Zolotitskoye field: Pomorskaya, Karpinskaya-1, Karpinskaya-2 and Arkhangelskaya pipes) has a high content of diamonds with yellowish-green tones of photoluminescence (PL). Another group has diamonds with prevalence of crystals with blue PL (Lomonosovskaya, Pionerskaya pipes). Shares of diamonds without PL and 
crystals with violet PL increase with decreasing of diamond size (Makhin, 1991; Zakharchenko, 1994). Most of crystals have a weak cathodoluminescence (CL). All crystals, studied by CL-method, have a zoning structure. Usually nucleus has yellow CL-color, and diamond-host with deformated structure has blue color (Garanin et al., 1997). Nitrogen contents in A-form vary on wide range: $(0-88) \times 10^{19} \mathrm{~cm}^{-3}$. There are large differences on distribution of Aform nitrogen between large and small diamond crystals. The crystals with small sizes (less 0.5 $\mathrm{mm}$ ) have low nitrogen concentrations usually. Most of studied diamonds are shown on tendence of decreasing of nitrogen concentration from core to peripheric part of crystals. It is a important fact that nitrogen concentration are relatively onstant inside cores and peripheries of crystals. A definite group of crystals has a sharp differences of A-form nitrogen concentration on the nucleous (16-19) $\times 10^{19} \mathrm{~cm}^{-3}$ and the peripheric parts (6-10) $\times 10^{19} \mathrm{~cm}^{-3}$. The $\mathbf{N} 3$ band system at $415 \mathrm{~nm}$ is discovered for cores of crystals only, and it is not present on peripheric parts. In such cases B-defects are present on cores of diamonds only and are shown on high roasting temperatures

of these nucleus which are responsible for aggregations A-defects and formation of B-defects. So discrete conditions of diamond mantle crystallization are established (Garanin et al., 1997).

\section{Gas inclusions}

Low volatile concentrations are typical for diamonds from the AKP. Composition of gases is simple. Inclusions are mixture of $\mathrm{CH}_{4}, \mathrm{H}$ and $\mathrm{CO}$ with prevalence of nitrogen and water. These facts are indicators on diamond cristallization at conditions of high oxidation potential (Makhin, 1991).

\section{Isotopic composition of carbon}

Determination of carbon isotopes was done for small collection of diamonds. There is large range of carbon: from -2.9 up $-22.2 \% \delta^{13} \mathrm{C}$. From all studied crystals approximately $10 \%$ belong to isotopic light diamonds with variations of $\delta^{13} \mathrm{C}$ from -10 up $-22.2 \%$. All data were determinated as integral characteristics for whole crystals. It future, it is necessary to investigate nucleus and peripheric parts of crystals separately (Zakharchenko, 1994).

\section{Mineral inclusions}

Crystals with heavy isotopic composition $\left(-2 \div-7 \% \quad \delta^{13} \mathrm{C}\right)$ contain mineral inclusions of ultrabasic paragenesis, and light isotopic ones have inclusions of eclogitic paragenesis. Chemical compositions of inclusions indicate on presence of different diamond-bearing associations in the AKP. The high-chromium spinels and high-magnesian low-aluminious orthopyroxenes from diamondiferous harzburgites, midium-ferrous olivines with higher $\mathrm{Ni}$ and $\mathrm{Cr}$ contents from diamondiferous lherzolites, high-magnesian chromediopsides with anomal higher Na-concentrations from diamondiferous lherzolites, high-chromium (knorringite) pyropes from diamodiferous dunites and harzburgites, low-calcium low- and medium-chromium pyropes from diamond-bearing equigranular lherzolites, pyrope-almandines from ilmenite-rutile diamondiferous magnesian-ferrous eclogites, also from disthene and corundum ones, and omphacite and coesite from aluminious diamondiferous eclogites were established (Sobolev et al., 1997) It is important fact that sulfides, wustite and native iron are not discovered as inclusions in diamonds from the AKP. It shows on the absence of mixing of upper and lower mantle flows. So microcrystals of diamonds with native iron-wustite-troilite paragenesis could not be nucleus for later crystallization of diamond of ultrabasic and eclogitic. It is a important difference diamonds from AKP compare with crystals from Yakutian province and other kimberlite province of the world. Also picroilmenite inclusions are apsent in diamonds of the AKP. It shows on magnesian character of primary mantle melt from which diamond paragenesis of minerals started to crystallize. 


\section{Genesis}

There are several diamond generations in the AKP. Mantle flows of lower parts of mantle had not remarkable influence for diamond formation. Initial stage of diamond crystallization started in the enviroment enriched by $\mathrm{H}_{2} \mathrm{O}$ and $\mathrm{CO}_{2}$. Oxidizing solution is a main reason for wide distribution of rounded diamonds in the kimberlites of the AKP. Presence of several diamond generations is outlined by wide range of nitrogen contents, and presence of inverse zoning is outlined by sharper changes of A-defects at transition from central parts to peripherical zones of crystals. The absence of picroilmenite inclusions in diamonds is an indicatorof higher magnesian and higher chromian composition of the mantle melt from which generations of ultramafic diamond paragenesis were crystallized.

\section{References}

Garanin, V.K. , Kudriavtseva, G.P. , Makhin, A.I. , and Possukhova, T.V. , 1991, Comparative morphological characteristic of diamonds from higher diamond-bearing and low grade kimberlite pipes of North Evroupean part of the USSR: VINITI, Moscow, \# 2493-B 91, p.219-246.

Garanin, V.K., Dummett, H. , Amthauer, G. , Kudriavtseva, G.P., and Fipke Ch., 1997, Internal structure and spectroscopic characteristics of diamond from the Lomonosov deposit: Proceed. RAN, v.2, \# 353, p. 223-227.

Makhin, A.I. , 1991, Crystallomorphology and physical features of diamonds from the Lomonosov deposit (Arkhangelsk diamondiferous province): Ph. D. Thesis, L'vov, $20 \mathrm{p}$.

Sobolev, N.V. , Yefimova, E.S. , Reimers, L.F. , Zakharchenko, O.D. , Makhin, A.I. , and Usova, L.V. , 1997, Mineral inclusions in the diamonds of Arkhangelsk kimberlite province: Geologiya i Geofizika, v.38, \#2, p. 358-3760.

Zakharchenko, O.D. , 1994, Typomorphic features of diamonds from South-East Belomoryie and their prospecting significance: $\mathrm{Ph}$. D. Thesis, Moscow, $29 \mathrm{p}$. 